Artículo de revisión

\title{
Evidencia de mutaciones genéticas asociadas con el albinismo en amerindios
}

\section{Evidence of genetic mutations associated with albinism in Amerindians}

\author{
다 Jaime Eduardo Bernal Villegas \\ Facultad de Medicina, Universidad del Sinú, Cartagena de Indias, Colombia \\ Artículo de posesión para el ingreso como miembro correspondiente a la \\ Academia Colombiana de Ciencias Exactas, Físicas y Naturales el 20 de octubre del 2019
}

\begin{abstract}
Resumen
Se revisan diversas descripciones históricas del albinismo entre los indígenas americanos para evidenciar cómo este error congénito del metabolismo ya se encontraba en América cuando los primeros conquistadores llegaron al continente, lo cual sugiere que por lo menos una de las mutaciones genéticas asociadas con el albinismo pudo haber llegado en el genoma de los primeros humanos que pasaron por el estrecho de Bering.

Palabras clave: albinismo; amerindios.

Abstract

Diverse historical descriptions of albinism among Amerindians are reviewed showing that this inborn error of metabolism was already present in America when the first conquistadores arrived in this continent, which suggests that at least one of the genetic mutations associated with albinism may have come in the genome of the first human migrants across the Bering Strait.
\end{abstract}

Keywords: Albinism; Amerindians.

\section{El albinismo}

El albinismo es una condición que, probablemente, se encuentra en todos los animales vertebrados, en muchos invertebrados y en algunas plantas; este trastorno genético heterogéneo es causado por mutaciones en diferentes genes, los cuales producen una reducción o ausencia total de melanina en los ojos, la piel, el pelo y en algunas otras estructuras. Hay tres tipos clínicos de albinismo: oculocutáneo, ocular y sindrómico. En la Tabla 1 se enumeran los siete genes conocidos causantes del albinismo oculocutáneo, así como el gen ligado a $\mathrm{X}$ responsable del albinismo ocular. El tercer tipo de albinismo es aquel que se encuentra asociado con otras condiciones clínicas como el síndrome de Hermansky-Pudlak, asociado con trastornos hemorrágicos y enfermedades intestinales y pulmonares, o el síndrome de Chédiak-Higashi, asociado con trastornos inmunológicos. Los defectos asociados con el albinismo oculocutáneo se transmiten de manera autosómica recesiva y, en consecuencia, se requieren mutaciones de ambos padres para producir sus signos y síntomas. El albinismo oculocutáneo ocurre en aproximadamente una de cada 40.000 personas a nivel global (Nord, 2015).
En su forma más dramática, la mutación de un gen codificado en el cromosoma 11, conocido como $T Y R$, causa la inactividad completa de la tirosinasa, una enzima necesaria para la producción de melanina, y una mutación diferente, codificada en el brazo largo del cromosoma 15, produce una forma alternativa de albinismo (Oculocutaneous albinism type 2, OCA2), que no es dependiente de la tirosina. Este tipo de albinismo presenta una distribución de uno en 36.000 individuos euroamericanos en los Estados Unidos, mientras que su frecuencia es mayor en amerindios, por ejemplo, en uno de 28 en Brasil y uno de 6.500 en el sur de los Estados Unidos (Woolf, 2005).

Asimismo, en varios estudios llevados a cabo en África se ha demostrado que también allí la condición es relativamente frecuente, como puede verse en la Tabla 2 (Hong, $\boldsymbol{e t}$ al., 2006). De hecho, se ha encontrado una deleción de 2,7 $\mathrm{Kb}$, la cual comprende el exón 7 del gen $O C A 2$, en varios

\section{Correspondencia:}

Jaime Eduardo Bernal Villegas; jebernal@gmail.com

Recibido: 2 de abril de 2019

Aceptado: 13 de agosto de 2019

Editor: Luis Fernando García 
Tabla 1. Siete genes conocidos causantes del albinismo oculocutáneo y el gen ligado a X responsable del albinismo ocular (datos tomados de Kamaraj \& Purohit, 2014)

\begin{tabular}{cccc}
\hline Nombre del gen & Gen & Ubicación & Número de mutaciones \\
\hline$O C A 1$ & Tirosinasa & $11 \mathrm{q} 14.3$ & $>300$ \\
$O C A 2$ & Gen P & $15 \mathrm{q} 11.2-\mathrm{q} 12$ & 154 \\
$O C A 3$ & Proteína relacionada con tirosinasa & $9 \mathrm{p} 23$ & 16 \\
$O C A 4$ & SLL45A2 & $5 \mathrm{p} 13.3$ & 78 \\
$O C A 5$ & ND & ND & 1 \\
$O C A 6$ & SLC24A5 & $15 \mathrm{q} 21.1$ & 2 \\
$O C A 7$ & C10orf11 & $10 \mathrm{q} 22.2$ & 1 \\
$O A 1$ & GPR143 & Xp22.3 & 114 \\
\hline
\end{tabular}

$\mathrm{ND}=$ no dato

Tabla 2. Albinismo en algunas poblaciones africanas (Hong, et al., 2006)

\begin{tabular}{ll}
\hline Región & Prevalencia \\
\hline Sur de África & $1: 3900$ \\
\hline - Xhosa & $1: 4794$ \\
- Sotho & $1: 2041$ \\
\hline - Swasi & $1: 2716$ \\
\hline - Tswana & $1: 3481$ \\
\hline Zimbabue & $1: 4922$ \\
\hline Tanzania & $1: 4000$ \\
\hline Nigeria & $1: 15000$ \\
\hline
\end{tabular}

africanos y afroamericanos no emparentados, lo que sugiere que provienen de un alelo fundador común cuyo origen se ha podido trazar hasta hace 2.000 a 3.000 años en una población surafricana y 4.100 o 5.645 años en una población del Camerún (Aquaron, et al., 2007). Algo similar se ha encontrado en India, donde las mutaciones en el gen $O C A 1$, halladas en 13 grupos étnicos que representan a cerca de 20 millones de individuos, parecen deberse, primordialmente, a mutaciones fundadoras en el gen de la tirosinasa (Chaki, $\boldsymbol{e t}$ al., 2006). Asimismo, en estudios realizados en la Polinesia se ha detectado en los tuvalu una sustitución sin sentido en la posición 775 del gen $O C A 2$, también encontrada en tres individuos de otro origen polinesio, pero ausente en otras comunidades melanesias, lo cual sugiere que esta mutación puede ser de origen polinesio y resultado, también, de un efecto fundador. Parece evidente, entonces, que el origen y la procedencia de las distintas mutaciones de los genes que causan el albinismo están lejos de haberse esclarecido. Ahora bien, el individuo albino tiene una serie de dificultades causadas por la enfermedad: la marcada sensibilidad a los efectos de la luz solar y los problemas visuales, lo que hace difícil explicar su larga historia en las poblaciones humanas $y$, sobre todo, su frecuencia significativamente mayor en las poblaciones subsaharianas y en los indígenas americanos. Ello supondría que el gen del albinismo confiere a su portador una ventaja selectiva, como sucede con los portadores del gen de la hemoglobina $\mathrm{S}$ y la resistencia a la malaria. En este sentido, en su estudio en Tanzania, Tuli, et al. (2012) han sugerido que la alta frecuencia de la tuberculosis y la lepra en esa región podría ser la clave para entender la asiduidad evidente de estas mutaciones en esas poblaciones.

\section{Antecedentes}

Uno de los antecedentes más interesantes en el registro histórico de la enfermedad en los grupos étnicos americanos se registra muy temprano en el siglo XVI, con la llegada de Hernán Cortés a Tenochtitlán el 8 de noviembre de 1519. En los siguientes seis años Cortés escribe cinco cartas "de relación" en las que narra al rey Carlos I los pormenores de la conquista de México. En la segunda de esas cartas, en medio del asombro ante la magnificencia de Tenochtitlán, refiere lo siguiente:

Tenía en esta casa un cuarto, en que tenía hombres, y mujeres, y niños, blancos de su nascimiento en el rostro y cuerpo y cabellos y cejas y pestañas (Cortés, [1520] 2016, p. 85).

Esta es la más temprana descripción del albinismo entre indígenas americanos, hecha en la misma casa de Montezuma, posiblemente a finales de 1519 o principios de 1520, y clara evidencia de la existencia de esta condición genética entre los aztecas muy poco después de la llegada de Colón a estas tierras.

Unos pocos años después, alrededor de 1530, el capitán Agustín Delgado fue enviado por el gobernador Jerónimo Ortal a explorar el interior de Venezuela. Fray Pedro Simón relata en su "IV Noticia Historial" que, al entrar Delgado al poblado del cacique Arcupón, el cual saqueó y arruinó, encontró lo que se describe a continuación:

Entre el saco que sacaron de este pueblo, no con poco estrago de haciendas y vidas, pues entre los demás perdió la suya peleando el cacique Arcupón, se hallaron 
cuatro chinas, que son indias de poca edad hasta que se casan, tan blancas, rubias y hermosas, como si se hubieran criado en Flandes, de que también se han hallado algunas en estos llanos, la tierra más adentro. $Y$ yo he visto una que se ha criado en esta ciudad de Santa Fe desde niña, tan blanca y rubia como hemos dicho. Preguntando los españoles si aquellas cuatro mujeres eran de otra nación circunvecina a este pueblo que fuesen todas de aquel color, respondieron ser nacidas y criadas en aquel pueblo, y que aquella blancura les venía de haber estado desde que nacieron tan encerradas, que jamás les habia cubierto el sol, como se echaba de ver, pues al modo de aves nocturnas, en sacándolas a él, se cubrían los ojos por lo mucho que les ofendía la luz (Simón, [1627] 1981, p. 446).

Pasarían 170 años antes de volverse a saber de algo similar en las relaciones de los cronistas. Lionel Wafer, cirujano galés, se asentó en Jamaica en 1676 para ejercer su profesión y, poco después, aceptó el cargo de cirujano en la flota de dos notables bucaneros, John Cook y Stephen Lynch. En 1680, en Cartagena de Indias, Wafer conoció a William Dampier, el célebre bucanero que circunnavegaría el globo tres veces, y se embarcó con él rumbo al istmo de Panamá para tomarse por tierra la población de Santa María. Cometido el asalto bajo el mando del mismo Dampier, parte de la tripulación decidió volver a hacer el largo camino a pie y en botes. Cinco días más tarde, la pólvora que secaba un marinero hizo explosión y destruyó la rodilla de Wafer de forma tan atroz que al poco tiempo debió ser abandonado por sus compañeros; otros dos marineros se quedaron con él en la mitad de la espesa y húmeda selva del Darién, desprovistos de vitualla alguna $\mathrm{y}$ en medio de los indios cuna. Tres meses tardaría Wafer en atravesar de sur a norte el istmo a partir de los primeros días de mayo de 1681 para reencontrarse con Dampier en el Caribe. Sus notas fueron publicadas por James y John Knapton en Londres, en 1699, con el título "A New Voyage and Description of the Isthmus of America”.

El texto está escrito en un lenguaje un poco lacónico pero rico en observaciones sobre la geografía, las plantas, las frutas, los insectos, los pájaros, los reptiles, los peces, y los "habitantes indios, sus maneras y costumbres". Después de hacer una descripción física de los indígenas Cuna, Wafer escribe:

Hay entre algunas gentes de este país un matiz de piel tan singular que nunca he visto ni oido en parte alguna del mundo. La descripción parecerá extraña, pero cualquier bucanero que haya estado en el istmo los habrá visto y podrá atestiguar sobre lo que voy a contar, aunque pocos habrán tenido la oportunidad que yo he tenido de obtener la información particular sobre estas gentes.

Son blancos y hay de ambos sexos; aunque hay pocos por comparación con los que tienen color cobre, posiblemente uno o dos por cada trescientos. Se diferencian de los demás indios especialmente por su color, aunque no solo en esto. Sus pieles son tan blancas como las de la gente más clara en Europa, con alguna tintura sonrojada o complexión sanguínea; pero no es su complexión totalmente como la de nuestra gente más pálida, más bien del color de la leche blanca, más clara que el color de cualquier europeo, muy semejante al de un caballo blanco. [...] Sus cejas son blanco leche, tanto como el cabello de sus cabezas [...].

No son tan altos como los demás indios; y lo que es más extraño, sus párpados se doblan y abren en una figura oblonga, apuntando hacia abajo en las esquinas, y formando un arco o figura de creciente con las puntas hacia abajo. De ahi, y por lo que ven claramente solo en las noches de Luna, acostumbrábamos llamarlos “ojilunos". No ven bien en el sol [...], sus ojos son muy débiles y les lloran si el sol brilla hacia ellos, por lo cual no salen durante el día si este no es oscuro y nublado (Wafer, 1699, p. 133-4).

Después de esta clara descripción del albinismo, su aparición en ambos sexos y su frecuencia en los indígenas del Istmo, Wafer relata:

Los Indios de color cobre no parecen respetarlos tanto como a los de su misma complexión, mirándolos como un tanto monstruosos. No son una raza distinta, pero en ocasiones uno surge de padre y madre color cobre; $y$ he visto un niño de menos de un año de esta suerte. Alguno podría sospechar que es hijo de un padre europeo: pero como pocos europeos vienen por aquí, y tienen poco comercio con las mujeres indias cuando vienen, esta gente blanca es tan diferente a los europeos en algunas medidas, como lo son de los indígenas color cobre en otras $[\ldots]$.

Pero nunca es blanco el hijo de un hombre o una mujer blancos, sino color cobre como sus padres (Wafer, 1699, p. 135-6).

Aunque algo confusa, esta aseveración podría interpretarse como la ausencia de albinos hijos de uno de sus padres albino, lo cual concuerda bien con el mecanismo de herencia autosómico recesivo de la condición. Sobre el origen de esta, Wafer relata la explicación que le diera uno de los indios:

Lacenta me dio esta explicación sobre cómo llegaron a ser blancos, que es a través de la fuerza de la imaginación de la madre, mirando a la Luna en el momento de la concepción. Pero dejo esto a otros para su interpretación. Me dijo, además, que su vida era corta (Wafer, 1699, p. 136).

Años más tarde hubo otro reporte de los albinos cuna. Corría el año de 1742 o 43 cuando se iniciaron las labores de los jesuitas en la provincia del Darién a instancias del rey y bajo el auspicio del virrey Sebastián de Eslava. Uno de los primeros jesuitas en llegar a la región fue el padre Jacobo Walburger, S. J., quien había nacido en Innsbruck 
en 1715 y llegó a la provincia de Quito en 1742. El padre Walburger inició la fundación de un pueblo en el sitio donde había existido el llamado Yaviza, en pleno tapón del Darién. En su "Breve Noticia de la Provincia del Darién", escrita en 1748, relata:

Lo propio sucede que la Yndia entierra una criatura, o la bota en el rio, quando la criatura es tula, y rara es la Yndia que cria tal criatura; porque no quieren ser padres de hijos que tengan semejanza en sus carnes con los españoles (Langebaek, 2006, p. 84).

En este relato, "tula" es una garza muy blanca, por lo que se refiere muy probablemente a una criatura albina y, por extensión, posiblemente al otro nombre, "tule", con que se conoce a los indígenas cuna.

\section{Reportes en el siglo XIX}

Un siglo más tarde, a principios de septiembre de 1847, el teniente William H. Emory, ingeniero topográfico del ejército norteamericano, casado con Matilde Wilkins, bisnieta de Benjamin Franklin, recibió instrucciones de presentarse en el fuerte Leavenworth en Missouri y ponerse al mando del coronel Kearny, quien lideraba una fuerza consistente en tres escuadrones bajo el comando del mayor Sumner, el primer regimiento de la caballería de Missouri, a su vez bajo el mando del coronel Doniphan y dos compañías de infantería a cargo del capitán Agney, que saldrían con la tarea de conquistar Nuevo Méjico. En sus apuntes publicados en 1848 bajo el título de "Notes of a Military Reconnaissance", Emory relata el viaje entre el fuerte de Leavenworth y San Diego, incluidos tramos de los ríos Arkansas, Gila y del Norte, donde refinaron las mediciones topográficas y recogieron especímenes de la flora local, y describe las costumbres de los grupos indígenas que encuentran a su paso:

Cerca del nacimiento de las aguas del Salinas, que corre en un curso que se dice del noreste al suroeste, hay una banda de indios llamados Soones, que en maneras y hábitos se parecen a los Pimos, excepto que viven en casas cavadas en la roca sólida. Muchos de ellos son albinos, lo que puede ser una consecuencia de su habitación en cavernas (Emory, 1848, p, 133).

Se trata evidentemente de los indios zuni o pueblo, asentados en los desiertos de Nuevo Méjico, al sur del río Colorado, y rodeados por los apache, navajo, pima y hopi, entre otros.

Unos cuantos años más tarde, en 1891, la Oficina de Etnología de los Estados Unidos publicó su noveno reporte anual bajo el título "The Medicine-Men of the Apache". El autor es John G. Bourke, capitán de la tercera caballería del ejército norteamericano. Bourke fue uno más de los soldados con intereses académicos que recorrieron el oeste norteamericano, como Emory, Sitgreaves, Whipple y Parke, para citar algunos más. Graduado en West Point, Bourke sirvió toda su vida como ayudante de campo del célebre general George Crook, quien le permitió, incluso, algunos tiempos para estudiar y vivir entre los indios de Arizona. Entre las muy notables observaciones de sus textos, hay una en el reporte anotado arriba que hace nuevamente alusión al albinismo:

Hay muchos ejemplos claros de albinismo entre los pueblos de Nuevo México y Arizona, especialmente entre los Zuñi y los Tasayán; pero no he sabido de ningún caso en que los individuos asi distinguidos se les acreditara con poderes no ascribibles a ellos bajo circunstancias ordinarias (Bourke, 1891, p. 460).

Los indios tasayán o tusayán son cercanos geográficamente a los hopi, pero de distinto origen lingüístico.

Hasta ahora hemos reseñado las palabras de militares, sacerdotes e incluso bucaneros que, gracias a su aguda observación, podrían llamarse "letrados" en el sentido de no cerrar los ojos a una realidad circundante ni circunscribirla a los limitados gajes de su oficio. A finales del siglo XIX hacen su aparición otras personas con diferentes antecedentes: Carl Lumholtz, un teólogo noruego con inclinaciones naturalistas que, tras permanecer cuatro años entre los aborígenes caníbales, decidió venir a estudiar a los indios de México. Lumholtz estuvo 20 años haciendo correrías por muy diversos sitios; varias son sus publicaciones sobre etnología y sobre el arte simbólico de los indios, pero la más citada es el libro "México desconocido" (1902) publicado en Londres. En el capítulo X del volumen I, el viajero noruego relata lo siguiente:

Cerca de Ohuivo, en las montañas hacia Morelos, vivía una familia de diez albinos. Cuando estuve allá solamente dos habian sobrevivido a la viruela. Su piel era tan delicada que hasta el contacto con la ropa la irritaba. El señor Hartman visitó a uno de ellos, una anciana que vivía en una cueva con su esposo, un tipo bajito y de piel oscura, y los dos ciertamente estaban casados, pero no eran semejantes. Sus características eran enteramente indias pero su apariencia era única en México, incluso entre la población blanca. Ella le recordaba a uno el tipo muy claro de los campesinos escandinavos o irlandeses. Su pelo era blanco amarillento, pero sus cejas y pestañas eran blanco nieve. La cara y el cuerpo eran blancos, pero con grandes manchas rojas y pequeñas pecas. Mantenía los ojos entrecerrados y como era muy tímida no se pudo ver su color de ojos, pero el marido le aseguró al señor Hartman que eran azulados (Lumholtz, 1902, p. 191).

\section{Siglo XX}

Matilda Coxe Stevenson, una mujer sin estudios universitarios pero con un vastísimo interés en los indígenas hopi, a los que venía analizando desde 1880, publicó en 1904, en el 23 reporte anual de la Oficina de Etnología de los Estados Unidos, un estudio sobre los indios zuñi, su mitología, fraternidades esotéricas y ceremonias (Twenty third annual report of the bureau of American ethnology to the secretary of the Smithsonian Institution 19011902 
https://archive.org/stream/annualreportofbu43smithso/ annualreportofbu43smithso djvu.txt. Allí dejó consignada la siguiente descripción, acompañada de la ilustración que se presenta a continuación (Figura 1):

En 1879, se encontraron siete albinos entre los Zuñis. El señor Stevenson logró, con dificultad, reunir a seis de ellos y tomarles una fotografia. No pudimos convencer a la madre de un niño albino que permitiera fotografiarlo. De hecho, son tan sensibles sobre su condición, que tratan de esquivar la presencia de extranjeros; los hombres lo ocultan menos, pero las mujeres y los niños vuelan a esconderse del americano. La escritora ha visto varios casos de niñas crecer a la adolescencia y llegar a adultas. En 1896 nació un niño albino. Estas gentes tienen el pelo amarillento y piel delicada. Todos tienen ojos débiles, y su visión está tan afectada por la ausencia del pigmento coroideo, que están obligados a protegerse los ojos, que se inflaman con la luz ordinaria del día. Cuando salen, el hombre albino usa sombrero y las mujeres se cubre las caras con mantas. Es errónea la creencia de que los albinos están obligados a vivir aparte de los otros de la tribu y no se les quitan sus privilegios religiosos o sociales. En ningún caso tiene un padre albino un hijo albino y no hay dos de la misma familia. Los adultos que se casan con indios de piel oscura tienen descendencia saludable (Coxe, 1904, p. 383).

Constituye este un análisis muy claro, con una perfecta descripción del fenotipo, el trastorno retiniano y el mecanismo de herencia de este trastorno, escrito cuatro años antes de que sir Archibald Edward Garrod le diera carta de naturalidad científica como error congénito del metabolismo en 1908 (Scriver, 2008).

Mientras Garrod reportaba las bases genéticas del albinismo en Europa, en ese mismo año de 1908 el Instituto Smithsoniano publicó el boletín número 34 titulado "Observaciones Fisiológicas y Médicas entre los Indios del Suroeste de los Estados Unidos y el Norte de México", firmado por Ales Hrdlicka, un antropólogo checo nacionalizado en los Estados Unidos y fundador del American Journal of Physical Anthropology, quien en este texto de 468 páginas recogió las observaciones hechas durante seis expediciones, de 1898 a 1905, en las que visitó casi todas las tribus del suroeste de los Estados Unidos (Hrdlika, 1908).

En palabras del autor en su introducción, "Estas expediciones fueron llevadas a cabo con el interés primario de la antropología física, pero, como médico, el autor tuvo oportunidades excepcionales para adquirir información de naturaleza médica y fisiológica”. Hrdlicka trató temas tan diversos como los tipos de medicina practicados por los indios, su demografía, características físicas y enfermedades, entre las cuales dedicó algunas páginas al albinismo. En marzo de 1900 el autor encontró 11 casos entre los hopi y seis entre los zuñi. La proporción en la población total fue de 5,5 por mil entre los hopi y de 3,8 por mil entre los zuñi. De los albinos hopi, tres eran hombres y ocho, mujeres, y de los zuñi, tres eran hombres y tres mujeres. Nueve de los 17 albinos eran niños y ocho, adultos.

Hrdlicka hace luego una descripción detallada del fenotipo, anotando las pequeñas variaciones entre unos y otros indios. Sobre los ojos dice:

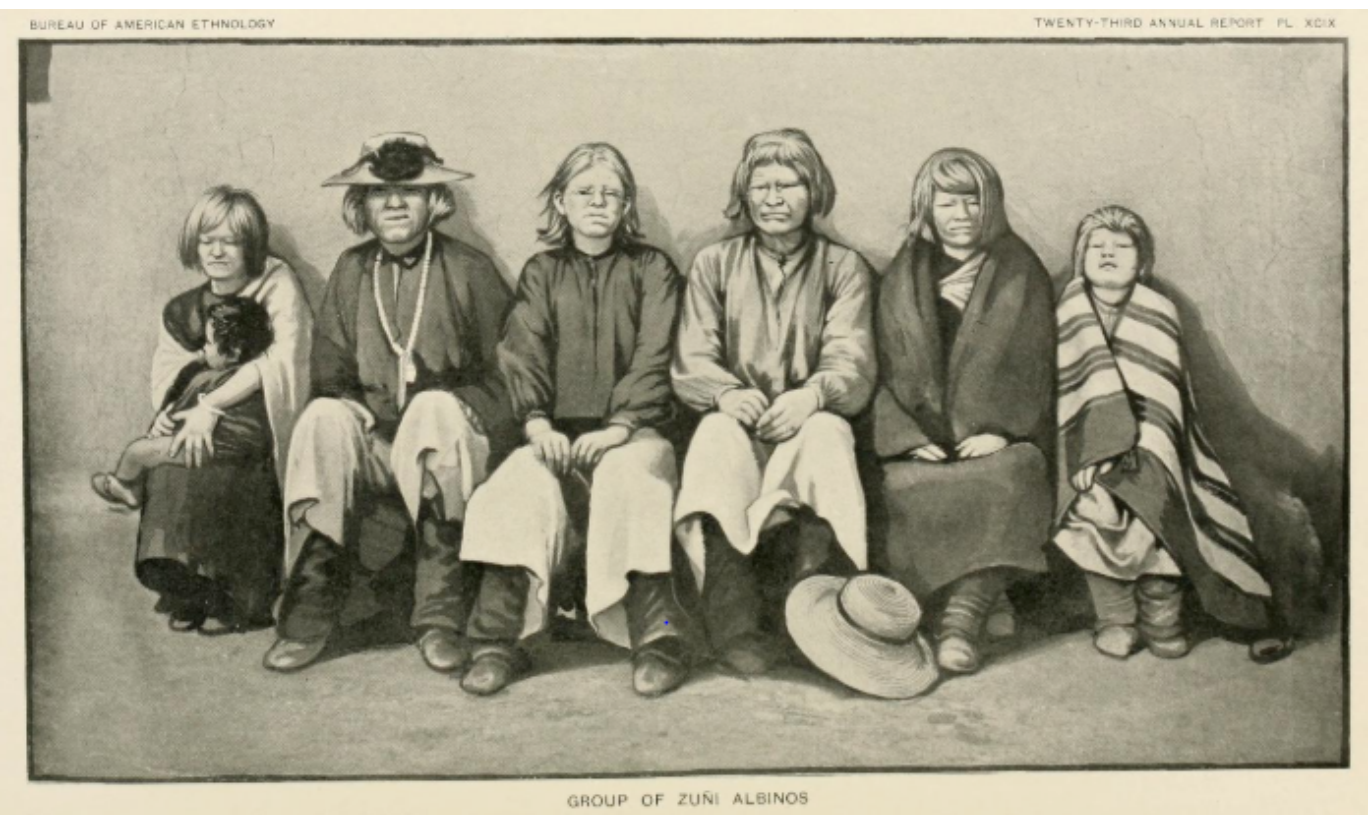

Figura 1. Ilustración de Coxe Stevenson de un grupo de indígenas zuñi albinos. Twenty third annual report of the bureau of American ethnology to the secretary of the Smithsonian institution $19011902 \mathrm{https}$ ://archive.org/stream/annualreportofbu43smithso/ annualreportofbu43smithso_djvu.txt 

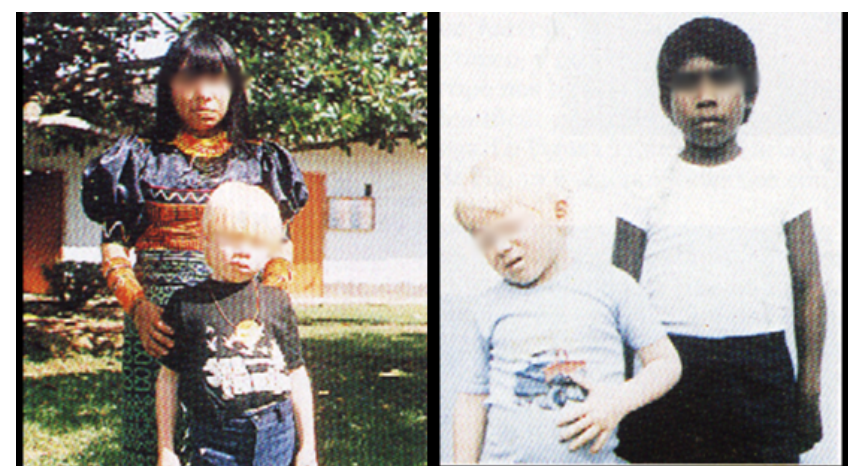

Figura 2. Albinos cuna y uitoto observados por el autor

Los ojos fueron entre gris claro o azul claro hasta azul grisoso, con la esclera blanca [...]. En ningún caso se encontró el iris sin color con un reflejo rosa como en el conejo albino. En todos los casos se encontraron nistagmus y heliofobia más o menos marcados (Hrdlika, 1908, p. 193).

Y sobre la historia familiar anota:

Las investigaciones sobre la historia familiar de un indio son raramente satisfactorias. De acuerdo a los escasos y no siempre confiables datos obtenibles, en la mayoría de los casos el albino fue el segundo hijo de la madre; en un caso fue el tercero y en otro el octavo [...]. En una familia el segundo y el sexto hijo fueron albinos, en otra el segundo y el tercero y, finalmente, una mujer tuvo tres hijos, todos albinos. En todos estos casos, el padre, la madre y los otros hijos, cuando los hay, eran de color normal. Los albinos casados con individuos de color normal raramente tienen hijos propios (Hrdlika, 1908, p. 194).

Por último, incluye sus comentarios sobre la etiología:

Hay indicaciones para pensar que la causa real y original de la condición está en los centros nerviosos, siendo de naturaleza degenerativa y propagada en la tribu a través de influencias hereditarias. No se encontraron conexiones con factores predisponentes en la serie aquí reportada. (Hrdlika, 1908, p. 194).

Los indígenas cuna vuelven a aparecer en la literatura biomédica en 1924, cuando Richard Marsh lleva a algunos de ellos a Estados Unidos, incluidos tres albinos, como parte de su prueba del descubrimiento de una raza de indios blancos (Marsh, 1925). Al año siguiente, George Harris llega a San Blas proveniente de los laboratorios de Cold Spring Harbor, se asienta casi dos meses entre los cuna y hace los primeros árboles genealógicos de individuos con albinismo. Observa que en ese lugar era prohibido el matrimonio de dos albinos, lo mismo que la común usanza del infanticidio en estos casos (Harris, 1926).

Por otra parte, en el Instituto de Genética Humana de la Facultad de Medicina de la Pontificia Universidad Javeriana hemos observado que el albinismo continúa presente en las poblaciones aborígenes de Colombia. En los múltiples viajes de la Expedición Humana liderada por el Instituto hemos podido estudiar más de 30 grupos indígenas colombianos $\mathrm{y}$ diversos asentamientos de población afrodescendiente en todo el territorio de nuestro país. Esta tarea nos ha permitido observar casos entre los yukuna, piaroa, embera y uitoto (como puede verse en la figura 2 y la tabla 3 ) lo que, aunado a los ya descritos en los cuna, arhuaco y yuko,

Tabla 3. Poblaciones nativas con casos de albinismo

\begin{tabular}{|c|c|c|c|}
\hline & Población & $\begin{array}{l}\text { Origen } \\
\text { lingüístico }\end{array}$ & Referencia \\
\hline \multirow{13}{*}{ Norteamérica } & Mayo & Uto-Azteca & Cortés, 1519 \\
\hline & & Uto-Azteca & Hrdlicka, 1908 \\
\hline & $\begin{array}{l}\text { Hopi } \\
\text { (tusayan?) }\end{array}$ & Uto-Azteca & $\begin{array}{l}\text { Hrdlicka, 1908; } \\
\text { Woolf, } 1965\end{array}$ \\
\hline & Tarahumara & Uto-Azteca & $\begin{array}{l}\text { Lumholtz, 1902; } \\
\text { Hrdlicka, } 1908\end{array}$ \\
\hline & Papago & Uto-Azteca & Hrdlicka, 1908 \\
\hline & Ute & Uto-Azteca & Hrdlicka, 1908 \\
\hline & Cheyene & $\begin{array}{l}\text { Algic- } \\
\text { Algonquian }\end{array}$ & $\begin{array}{l}\text { Bourke, 1892; } \\
\text { Hrdlicka, } 1908\end{array}$ \\
\hline & Menominee & $\begin{array}{l}\text { Algin- } \\
\text { Algonquian }\end{array}$ & Hrdlicka, 1908 \\
\hline & San juan & Na-dené & Woolf, 2005 \\
\hline & Navajo & Na-dené & Woolf, 2005 \\
\hline & Zuni & $\begin{array}{l}\text { Lengua } \\
\text { aislada }\end{array}$ & $\begin{array}{l}\text { Emory, 1848; } \\
\text { Hrdlicka, } 1908\end{array}$ \\
\hline & Chikkasah & Muskogean & Woolf, 2005 \\
\hline & Crow & Siouan & Hrdlicka, 1908 \\
\hline \multirow{3}{*}{ Centroamérica } & $\begin{array}{l}\text { Lacandon- } \\
\text { maya }\end{array}$ & Mayan & Woolf, 2005 \\
\hline & Quiche-maya & Mayan & Witkop, 1971 \\
\hline & Cuna & Chibcha & Fairchild, 1924 \\
\hline \multirow{10}{*}{ Suramérica } & Guatuso & Chibcha & $\begin{array}{l}\text { Jeambrun \& } \\
\text { Sergent, } 1991\end{array}$ \\
\hline & Guaymi & Chibcha & $\begin{array}{l}\text { Jeambrun \& } \\
\text { Sergent, } 1991\end{array}$ \\
\hline & Arhuaco & Chibcha & $\begin{array}{l}\text { Jeambrun \& } \\
\text { Sergent, } 1991\end{array}$ \\
\hline & Zapara & $\begin{array}{l}\text { Zaparoana } \\
\text { (¿Arawak?) }\end{array}$ & $\begin{array}{l}\text { Jeambrun \& } \\
\text { Sergent, } 1991\end{array}$ \\
\hline & Yukpa & Caribe & $\begin{array}{l}\text { Jeambrun \& } \\
\text { Sergent, } 1991\end{array}$ \\
\hline & Yucuna & Arawak & $\begin{array}{l}\text { Bernal, et al., } \\
1994\end{array}$ \\
\hline & Piaroa & Sáliva & $\begin{array}{l}\text { Bernal, et al., } \\
1994\end{array}$ \\
\hline & Embera & Chocó & $\begin{array}{l}\text { Bernal, et al., } \\
1994\end{array}$ \\
\hline & Uitoto & Uitoto & $\begin{array}{l}\text { Bernal, at al., } \\
1993\end{array}$ \\
\hline & Caingang & $\mathrm{Ge}$ & Salzano, 1961 \\
\hline
\end{tabular}


sugiere claramente que por lo menos una de las mutaciones asociadas con el albinismo pudo haber cruzado el estrecho de Bering en la etapa del poblamiento temprano de América, configurando un efecto fundador ancestral en los indígenas del Nuevo Continente.

\section{Conclusiones}

La revisión histórica de las variadas descripciones de la presencia de individuos albinos en poblaciones indígenas del Nuevo Continente, iniciada con la visita de Hernán Cortés a Montezuma en 1519 y seguida por las de piratas, exploradores, militares y aficionados que viajaron al continente y dejaron escritas observaciones pertinentes en sus memorias de viajes, sugiere que, dado el gran número de grupos indígenas de diversas lenguas en que se han encontrado casos de albinismo, por lo menos uno de los genes responsables de esta condición pudiera haberse transmitido a partir de alguna de las ondas migratorias de los primeros pobladores del continente.

\section{Conflicto de intereses}

El autor no tiene conflicto de intereses.

\section{Referencias}

Aquaron, N., Soufir, J.L., Berge-Lefranc, C., Badens, C., Austerlitz, B., Grandchamp, B. (2007) Oculocutaneous albinism type 2 (OCA2) with homozygous $2.7 \mathrm{~Kb}$ deletion of the $\mathrm{P}$ gene and sickle cell disease in a Camaroonian family. Identification of a common TAG haplotype in the mutated P gene. J Hum Genet. 52: 771-780.

Bernal, J.E., Briceño, I., Duncan, R. (1993). El arte del chamanismo, la salud y la vida: Tumaco - La Tolita. Bogotá: Pontificia Universidad Javeriana.

Bernal, JE. (1994). Observaciones del autor tomadas de las notas de viaje e historias clínicas de los grupos visitados por la Expedición Humana (1983-1993). Disponibles en el archivo histórico de la Pontificia Universidad Javeriana.

Bourke, JG. (1892). The Medicine-Men of the Apache. Ninth annual report of the Bureau of Ethnology to the Secretary of the Smithsonian Institution 1887-88 by JW Powell, Director. Glorieta, NM: Rio Grande Press.

Chaki, M., Sengupta, M., Mukhopadhyay, A., Subba Rao, I., Majumder, P.P., Das, M., Samanta, S., Ray, K. (2006) OCA1 in different ethnic groups of India is primarily due to founder mutations in the tyrosinase gene. Ann Hum Genet. 70 (5): 623-630.

Cortés, H. Segunda relación [30 de octubre de 1520]. Cartas de relación. https://freeditorial.com/es/books/cartas-de-relacion

Coxe-Stevenson, M. (1904). Zuñi and the Zuñians. https://archive. org/details/zuizunians00stev/page/22

Emory, W.H. (1848). Notes of a Military Reconnaissance, from Fort Leavenworth, in Missouri, to San Diego, in
California, including part of the Arkansas, Del Norte, and Gila Rivers. Washington: Wendell and Van Benthuysen, printers (JEB)

Fairchild, H.L. (1924). White Indians of Darien. Science. 60: 235-237.

Harris, G. (1926). The San Blas Indians. American Journal of Physical Anthropology. 9: 17-58.

Hong, E.S., Zeeb, H., Repacholi, M.H. (2006). Albinism in Africa as a public health issue. BMC Public Health. 6: 212.

Hrdlicka, A. (1908). Physiological and medical observations among the indians of southwestern United States and northern Mexico. Washington: Government Printing Office. https://repository.si.edu/handle/10088/15501

Jeambrun, P. \& Sergent, B. (1991): Les enfants de la lune. L'albinisme chez les Amerindiens. Paris: INSERMORSTOM.

Kamaraj, B., Purohit, R. (2014) Mutation analysis of oculocutaneous albinism: A complete review. Biomed. Res. Int. 214: 905472.

Langebaek, C.H. (2006). El Diablo vestido de negro y los Cunas del Darién en el siglo XVIII. Bogotá: Ediciones Uniandes.

Lumholtz, C. (1902). Unknown Mexico. A record of five years' exploration among the tribes of the Western Sierra Madre; in the Tierra Caliente of Tepic and Jalisco; and among the Tarascos of Michoacan. http://www.gutenberg.org/ etext $/ 16426$

Marsh, R. (1925). The mystery of the white Indians. The World's Work. 49: 633-645.

National Organization for Rare Disorders - NORD. (2015). Oculocutaneous albinism www.rarediseases.org/rarediseases/oculocutaneous-albinism

Salzano, F.M. (1961). Rare genetic conditions among the Caingang Indians. Annals of Human Genetics. 25: 123-130.

Scriver, C.R. (2008). Garrod's Croonian Lectures (1908) and the charter 'Inborn Errors of Metabolism': Albinism, alkaptonuria, cystinuria, and pentosuria at age 100 in 2008. Journal of Inherited Metabolic Diseases. 31 (5): 580-598.

Simón, Fray P. ([1627] 1981). Noticias historiales de las conquistas de tierra firme en las Indias occidentales. Bogotá: Biblioteca Banco Popular.

Tuli, A.M., Valenzuela, R.K., Kamugisha, E., Brilliant, M.H. (2012). Albinism and disease causing pathogens in Tanzania: Are alleles that are associated with OCA2 being maintained by balancing selection? Med Hypothesis. 79 (6): 875-880.

Wafer, L. (1699). A New Voyage and Description of the Isthmus of Darien. Londres: Knapton. https://www.biodiversitylibrary. org/item/103939\#page/154/mode/1up

Witkop, C.J. (1971). Albinism. En: Harris H, Hirschorn, K, editores. Advances in Human Genetics. New York: Plenum, p. 61-142.

Woolf, C.M. (1965). Albinism among Indians in Arizona and New Mexico. American Journal of Human Genetics. 17: 23-35.

Woolf, C.M. (2005). Albinism (OCA2) in Amerindians. Yearbook of Physical Anthropology. 48: 118-140. 